\title{
Melon necrotic spot virus Replication Occurs in Association with Altered Mitochondria
}

\author{
Cristina Gómez-Aix, ${ }^{1}$ María García-García, ${ }^{2}$ Miguel A. Aranda, ${ }^{1}$ and María Amelia Sánchez-Pina ${ }^{1}$ \\ ${ }^{1}$ Centro de Edafología y Biología Aplicada del Segura (CEBAS)-CSIC, P.O. Box 164, 30100 Espinardo, Murcia, Spain; \\ ${ }^{2}$ Servicio de Ayuda a la Investigación, Servicio de Microscopía, Universidad de Murcia, Campus de Espinardo, 30100 \\ Espinardo, Murcia, Spain
}

Submitted 19 September 2014. Accepted 25 October 2014.

\begin{abstract}
Melon necrotic spot virus (MNSV) (genus Carmovirus, family Tombusviridae) is a single-stranded, positive-sense RNA virus that has become an experimental model for the analysis of cell-to-cell virus movement and translation of uncapped viral RNAs, whereas little is known about its replication. Analysis of the cytopathology after MNSV infection showed the specific presence of modified organelles that resemble mitochondria. Immunolocalization of the glycine decarboxylase complex (GDC) $\mathbf{P}$ protein in these organelles confirmed their mitochondrial origin. In situ hybridization and immunolocalization experiments showed the specific localization of positive-sense viral RNA, capsid protein (CP), and double-stranded (ds)RNA in these organelles meaning that replication of the virus takes place in association with them. The three-dimensional reconstructions of the altered mitochondria showed the presence of large, interconnected, internal dilations which appeared to be linked to the outside cytoplasmic environment through pores and/or complex structures, and with lipid bodies. Transient expression of MNSV p29 revealed that its specific target is mitochondria. Our data document the extensive reorganization of host mitochondria induced by MNSV, which provides a protected environment to viral replication, and show that the MNSV p29 protein is the primary determinant of this effect in the host.
\end{abstract}

The replication of single-stranded positive-sense RNA viruses takes place in association with rearrangement of host membranes by the virus (Laliberté and Sanfaçon 2010). These membrane rearrangements are supposed to (i) provide a scaffold to anchor replication complexes, (ii) favor the local concentration of viral replication enzymes, and (iii) provide isolation against plant defense systems. These modifications include either membrane proliferation and the formation of vesicles, the so-called multivesicular bodies in different cell organelles, or both (Grangeon et al. 2012). Organelle specificity varies among families, genera, or virus species (Laliberté and Sanfaçon 2010). Members of the genus Tombusvirus (family Tombusviridae) induce the formation of membranous multivesicular bodies or cytoplasmic inclusions (Russo et al. 1987). Multivesicular bodies consist of a central body surrounded by

Corresponding author: María Amelia Sánchez-Pina;

E-mail: spina@cebas.csic.es; Telephone: +1 34-968396307;

Fax: +1 34-968396213.

*The $\boldsymbol{e}$-Xtra logo stands for "electronic extra" and indicates that four supplementary figures and three supplementary movies are published online.

() 2015 The American Phytopathological Society numerous vesicles containing fibrillar material with doublestranded RNA (dsRNA) and have been proposed to be their replication sites (Appiano et al. 1986; Russo et al. 1983). Studies with members of the family Tombusviridae have shown that ORF 1 protein is responsible for the subcellular localization of the replication complex. Hence, ORF 1 products from Red clover necrotic mosaic virus (genus Dianthovirus) and Panicum mosaic virus (genus Panicovirus) have been localized to the endoplasmic reticulum (ER) (Batten et al. 2006; Turner et al. 2004), ORF1 products from Tomato bushy stunt virus (TBSV), Cymbidium ringspot virus, and Cucumber necrosis virus (genus Tombusvirus) to peroxisomes (McCartney et al. 2005; Navarro et al. 2004; Panavas et al. 2005), and from Carnation Italian ringspot virus (genus Tombusvirus) and Pelargonium flower break virus (genus Carmovirus) to mitochondria (Martínez-Turiño and Hernández 2010, 2012; Weber-Lotfi et al. 2002). An interesting feature that appeared in other tombusviruses is the use of alternative subcellular membranes, such as ER instead of peroxisomes, for TBSV replication when the preferred membrane becomes limited (Jonczyk et al. 2007).

The genome of Melon necrotic spot virus (MNSV) (genus Carmovirus, family Tombusviridae) is composed of a singlestranded positive-sense RNA of $4.3 \mathrm{~kb}$, with at least five open reading frames (ORF) (Riviere and Rochon 1990) flanked by two untranslated regions (UTR) at their $5^{\prime}$ and $3^{\prime}$ termini. The $3^{\prime}$ ORF encodes the capsid protein $(\mathrm{CP})$ which, in addition to its structural role, is necessary for vascular transport of the virus, plays a role in suppression of RNA silencing (Genovés et al. 2006), and is involved in virus transmission (Ohki et al. 2010). The two small, centrally located ORF are the double gene block of carmoviruses, which encodes two consecutive proteins of 7 $\mathrm{kDa}(\mathrm{p} 7 \mathrm{~A}$ and $\mathrm{p} 7 \mathrm{~B})$ involved in the cell-to-cell movement of the virus (Genovés et al. 2006; Navarro et al. 2006). The 5' ORF has the potential to encode a protein of $29 \mathrm{kDa}(\mathrm{p} 29)$ ending in an amber codon whose read-through could give a larger gene product of $89 \mathrm{kDa}(\mathrm{p} 89)$, containing the RNAdependent RNA polymerase (RdRp) domain; p89 and p29 are involved in viral replication (Genovés et al. 2006; Riviere and Rochon 1990). MNSV has become an experimental model for the analysis of aspects related to resistance breaking, translation of uncapped viral RNAs, and cell-to-cell movement. It has been shown that the 3' UTR of genomic MNSV RNAs, that are identical to those of subgenomic RNAs, contain sequences that act as cap-independent translation enhancers ( $3^{\prime}$ CITEs) (Miras et al. 2014; Truniger et al. 2008). Moreover, the resistancebreaking ability in melon and Nicotiana benthamiana depend on the specific nature of these 3' CITEs (Nieto et al. 2006, 2011; Truniger et al. 2008), which can be exchanged through recombination among viral strains or even viral species (Díaz 
et al. 2004; Miras et al. 2014). It has also been shown that MNSV cell-to-cell movement requires the sequential transport of $\mathrm{p} 7 \mathrm{~B}$ from the ER via the Golgi to plasmodesmata in a COPIIdependent pathway (Genovés et al. 2010; Navarro et al. 2006).

Characterizing the cell endomembranes that the virus exploits as the sites of viral replication and the role of viral proteins in this process can significantly contribute to a better understanding of the viral cycle. In order to do so, we have analyzed the subcellular alterations caused by MNSV. The results show that MNSV induces deep modifications of the mitochondrial ultrastructure, where MNSV positive sense RNA, $\mathrm{CP}$, and dsRNA localize specifically. We have also studied the three-dimensional (3D) structure of the altered mitochondria, showing that they contain large internal interconnected dilations, a characteristic that has not been described previously in other viral replication structures. Moreover, these internal dilations are likely to be linked to the outside cytoplasmic environment through pores or complex structures or both and with lipid bodies. By transiently expressing MNSV p29, we have revealed the specific targeting of this protein to mitochondria and its ability to induce significant alterations in this organelle. Thus, our results strongly suggest that MNSV viral factories originate by the alteration of mitochondria, primarily through the action of the MNSV p29 protein.

\section{RESULTS}

\section{Ultrastructure of MNSV infected cells.}

MNSV induces the formation of necrotic lesions in inoculated and systemically infected tissues. In MNSV-inoculated melon cotyledons, chlorotic spots of approximately $2 \mathrm{~mm}$ in diameter are visible at 3 days postinoculation (dpi) which become necrotic and grow, reaching approximately $5 \mathrm{~mm}$ at 7 dpi (Miras et al. 2014).

In order to study the ultrastructural changes induced by MNSV, we selected chlorotic spots $3 \mathrm{dpi}$, before the development of necrosis. We first studied the cell structure on toluidine bluestained semithin sections in order to check the structural preservation of the tissue. We observed a central area of necrotic cells (Fig. 1A) surrounded by nonnecrotic cells with different structural changes. Among these changes, the most striking one was the presence of strange cytoplasmic organelles that could reach sizes even larger than chloroplasts. These organelles were present in all cellular types of the infected tissue (Fig. 1B through E).

The study of the cytopathology by transmission electron microscopy (TEM) showed normal ultrastructural features in organelles such as chloroplasts, peroxisomes, or nuclei of healthy and infected plants (Fig. 2A). In infected cells, very few mitochondria were observed and the abnormal organelles resembling mitochondria showed significant changes in shape and internal structure (Fig. 2B through G). The ultrastructural changes included dilated cristae, a clear separation of the double membrane of the mitochondrial matrix, and quite large dilations inside them (Fig. 2B and C), structural features not present in the healthy plant mitochondria (Fig. 2A). The most striking ultrastructural changes present in infected cells were the abnormal organelles (Fig. 2D through G) that contained large dilations and were frequently observed close to lipid bodies (Supplementary Fig. S1A) and ER membranes (Fig. 2E and F). The main characteristic of these organelles was the presence of numerous vesicles of 45 to $50 \mathrm{~nm}$ in length along their external membrane and in the internal lumen of the large dilations (Fig. 2E through $\mathrm{G})$. These vesicles were often bottle-shaped and seemed to derive from the external mitochondrial membrane, opening toward the cytoplasm and showing a close relationship between the organelle and the ER (Fig. 2F, white arrows). Vesicles within large dilations surrounded the whole dilation and opened to the dilation lumen (Fig. 2G, white arrows). These abnormal organelles could reach quite large sizes $(2 \mu \mathrm{m}$ wide and $3.5 \mu \mathrm{m}$ long on average) and dilations inside them occupied up to $80 \%$ of the total area showing vesicles that opened to the lumen of the dilation, depending on the plane of the section and the stage of the organelle (Fig. 2E and G). Viral-like particles (VLP) were observed either dispersed inside the organelle, adjacent to it, or forming aggregates in the cytoplasm. These organelles were frequently located close to plasmodesmata. Dense clusters of amorphous material were also observed in the cytoplasm of infected cells.

\section{Characterization of abnormal organelles in MNSV-infected cells.}

In order to confirm the mitochondrial origin of the abnormal organelles induced by MNSV, we carried out immunolocalization experiments of the GDC $\mathrm{P}$ protein, a mitochondriaspecific enzyme (Palmieri et al. 2010). The labeling of healthy tissue was very specific for plant mitochondria, with gold particles being observed in most of the mitochondria analyzed (Fig. 3A) but not in other cytoplasmic organelles, such as peroxisomes (Fig. 3B). In samples from infected plants, 20 analyzed abnormal organelles contained gold particles (832 particles) (Fig. 3C), whereas labeling was absent in peroxisomes and other cellular organelles, demonstrating that the location of gold particles was very specific; labeling was mostly restricted to the abnormal organelle matrix $(94.2 \%)$, since few particles were detected in the dilations of them (2.3\%) (Fig. 3C) and, also, few $(3.5 \%)$ were in the cytoplasm. These results, together with the ultrastructural observations, indicate that abnormal organelles are, in fact, altered mitochondria.

In order to determine the relationship between the altered mitochondria and MNSV, we localized positive sense viral RNAs by in situ hybridization (ISH). A strong hybridization signal was observed in all samples from infected tissues, mainly in the big dilations of the altered mitochondria and in the cytoplasm of the cells containing them (Fig. 4A through C). Immunolocalization of the $\mathrm{CP}$ antibody provided similar results, showing a higher density of gold particles in the altered mitochondria and in the cytoplasm of the infected cells (Fig. 4D through F). These results suggested that these altered mitochondria could constitute the sites of MNSV replication. Thus, we used dsRNA as a marker of viral replication intermediates (Schönborn et al. 1991; Westaway et al. 1999) and found that labeling with an antibody to detect dsRNA was very specific of infected cells and was mainly localized in the altered mitochondria and adjacent cytoplasm (Fig. 4G through I). Western blot experiments for the anti-CP polyclonal antibody (Supplementary Fig. S2) as well as control experiments in healthy plant cotyledons (Supplementary Fig. S3) were performed in order to check the specificity of the labeling.

\section{D reconstruction of altered mitochondria by focused ion beam-field emission scanning electron microscopy.}

Observations made by TEM could be explained by at least two alternative hypotheses. On the one hand, the apparent inner big mitochondrial dilations may correspond to large invaginations of the mitochondrial outer membrane resulting in cytoplasmic intrusions, like fingers of a glove turned inside out. On the other hand, the apparent inner dilations could be genuinely inside the organelle, arising from the mitochondrial lumen. To distinguish between these two hypotheses and to understand the overall architecture of the organelle as well as the contribution of the mitochondrial membranes in generating the MNSV replication bodies, we performed 3D reconstruction from images obtained by focused ion beam-field emission scanning electron microscopy (FIB/FESEM). 
Altered mitochondria appeared to be surrounded by a continuous membrane (Fig. 5) and showed the presence of small vesicles in the external surface as well as inside the big dilations at TEM (Fig. 5A). Supplementary Movie S1 clearly shows how the dilations of the organelle are closing and opening, while in a semitransparent representation the presence of up to 5 of these internal dilations are observed (Fig. 5B, Supplementary Movie $\mathrm{S} 2)$. 3D reconstruction also showed the existence of connections between different altered mitochondria (Fig. 5B and C; Supplementary Movie S3) and between altered mitochondria and lipid bodies (Fig. 5B, J, and K). Contacts between lipid bodies and altered mitochondria were observed in a variety of orientations showing clear connections between them (Fig. 5B, $\mathrm{J}$, and $\mathrm{K}$ ). A study of the sequence of images obtained by FIB/ FESEM allowed the identification of small pores in the membrane connecting the lumen of the dilations with the cytoplasm (Fig. 5D to I). These pores were also observed in the 3D reconstruction obtained from sections 0001 to 0065 (Fig. 5D to I) when the organelle is turned 180 degrees (Fig. 5J and K). In the $3 \mathrm{D}$ reconstruction, the existence of connections between different dilations inside the altered mitochondria can also be observed (Fig. 5K). Therefore, our results demonstrate that the large dilations observed in altered mitochondria are internal compartments that are interconnected and are possibly connected to the outside environment of the altered mitochondria through either pores, or complex structures, or both.

\section{MNSV p29 induces the mitochondrial alterations.}

The MNSV p29 protein has been identified as being responsible for the induction of necrosis in $N$. benthamiana plants, and this was associated with its ability to be targeted to the mitochondria (Mochizuki et al. 2009). However, the relationship between p29 and the formation of MNSV replication-related structures is unknown. Given the lack of specificity of the available p29 antibodies, a plasmid that allowed monitoring of the expression of a p29-green fluorescent (GFP) fusion protein was generated. Since transient expression of p29-GFP in melon was insufficient in terms of fluorescence visualization using confocal laser scanning microscopy (CLSM) (data not shown), these experiments were performed in $N$. benthamiana plants. Ultrathin sections of $N$. benthamiana leaves inoculated with MNSV-264, a strain capable of infecting this host (Nieto et al. 2011), were analyzed in order to check for the presence of mitochondria-derived organelles. TEM analysis of these tissues showed mitochondrial structural changes and the presence of large altered mitochondria in advanced stages of degradation (Supplementary Fig. S4A to C). No ultrastructural alterations were observed in other organelles, except for some chloroplasts containing virus-like particles. Thereafter, subcellular localization of p29-GFP was determined by CLSM analysis of transient expression in $N$. benthamiana plants. In agroinfiltrated plants, we observed the presence of punctuated fluorescence structures (Fig. 6), distributed throughout the cytoplasm, that were arranged around chloroplasts without overlapping with them (Fig. $6 \mathrm{~A}$ through $\mathrm{C}$ ). Coexpression of $\mathrm{p} 29-\mathrm{GFP}$ with various organelle markers in vivo (Nelson et al. 2007) resulted in colocalization of p29-GFP with the mitochondrial marker (Fig. 6D through F), which was not observed with the peroxisome marker (Fig. 6G through I). These results showed the ability of ectopically expressed p29-GFP to target mitochondria in agroinfiltrated tissues.

At the ultrastructural level, $N$. benthamiana plants agroinfiltrated with p29-GFP showed numerous changes and dilations in mitochondria (Fig. 7A) that were not detected in healthy plants (Fig. 7B). Mitochondria showed proliferation of double membranes around the dilations induced in these organelles (Fig. 7C through E). Generally, the mitochondria ultrastructural changes were very similar to those induced by the virus (Fig. 7E). Immunolocalization of p29-GFP, by using an anti-GFP antibody, confirmed the results obtained by CLSM, showing a very specific labeling of p29-GFP, mainly located in the double membrane structures surrounding the dilations of affected mitochondria (Fig. 7C through E).

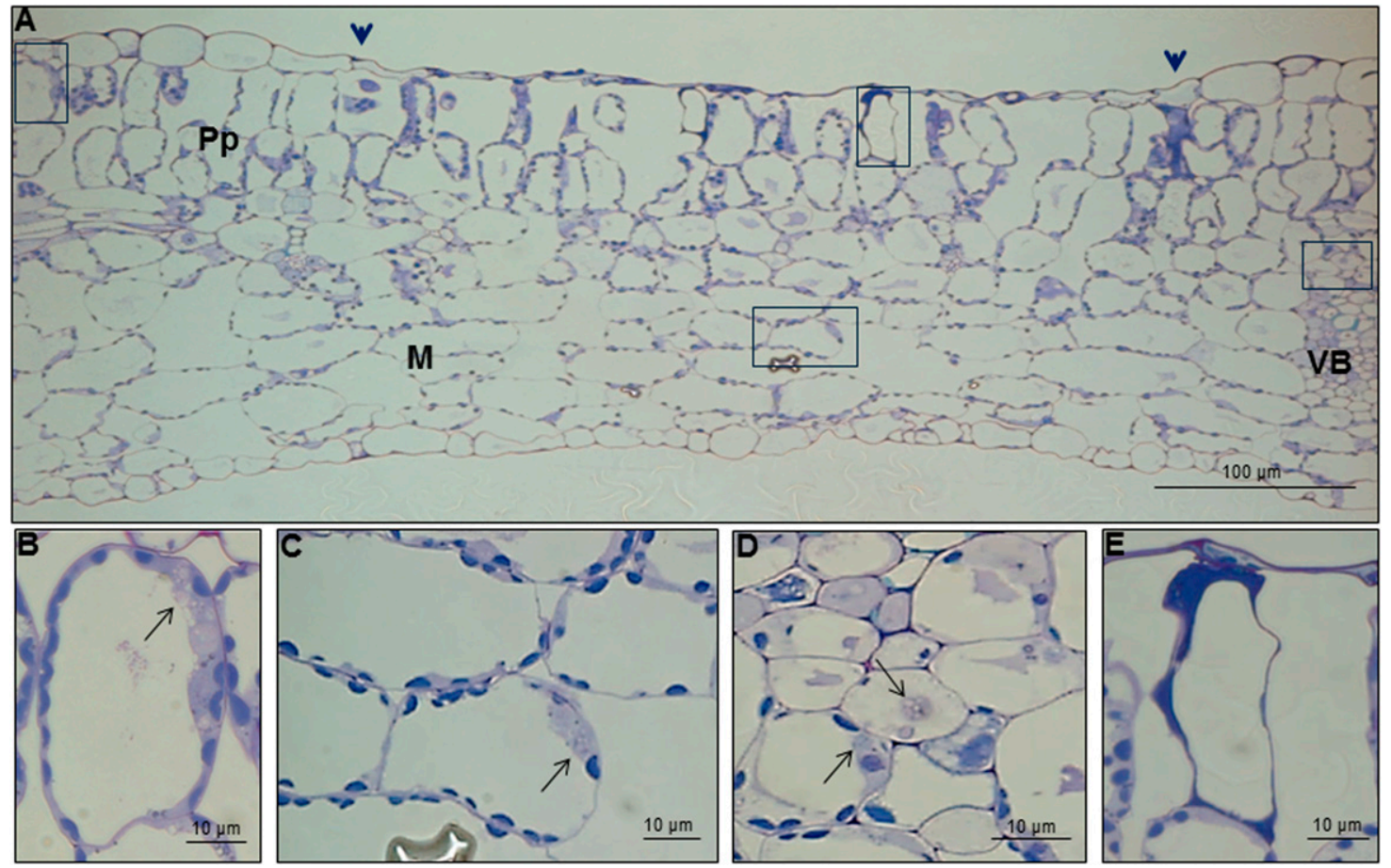

Fig. 1. Cytopathology of Melon necrotic spot virus (MNSV) lesions by toluidine blue staining at light microscopy on Spurr-embedded samples. A, Cross section of a lesion showing the boundaries of the necrotic region. Arrowheads point to the limits of the area of collapsed epidermal cells. B through $\mathbf{E}$, Inside and outside the necrotic zone, cells contain abnormal organelles (arrows), and cytopathological alterations. B, Palisade parenchyma cell (Pp). C, Mesophyll cell (M). D, Vascular bundle cells (VB). E, Necrotic palisade parenchyma cell. 
According to these results, the p29 protein is able to specifically target mitochondria, where it could induce its reorganization and the formation of structures with numerous dilations surrounded by double membranes. This membrane proliferation in the organelle might be required for formation of the vesicles, making it the organelle in which the viral RNA replication could take place together with other viral and host functions.

\section{DISCUSSION}

Most eukaryotic (+) single-straded RNA viruses replicate in association with cell membranes. Often, these viruses induce changes such as proliferation or invagination of membranes to create structures that allow assembly of replication proteins (Ahlquist 2006; Fernández de Castro et al. 2013; Laliberté and Sanfaçon 2010; Mine and Okuno 2012; Netherton et al. 2007).
Previous work with different members of the family Tombusviridae revealed the formation of vesicular structures in different organelles, generally peroxisomes (Martelli et al. 1984; Russo et al. 1983; Panavas et al. 2005) or mitochondria (Di Franco and Martelli 1984), that were suggested to be the place where viral replication took place. Ultrastructural analysis of MNSV-induced lesions allowed identification of abnormal organelles that derive from mitochondria, as confirmed by immunolocalization of GDC $\mathrm{P}$ protein, a key enzyme of the photorespiratory $\mathrm{C} 2$ cycle in C3 plants (Palmieri et al. 2010). Immunolocalization of $\mathrm{CP}$ and dsRNA showed that MNSV replication could take place in those altered mitochondria. From these organelles, viral progeny would be generated and released to the cytoplasm, in agreement with our results of the in situ detection of positive sense viral RNA in both the altered mitochondria and cytoplasm (Fig. 4A through C). These organelles appear to contain
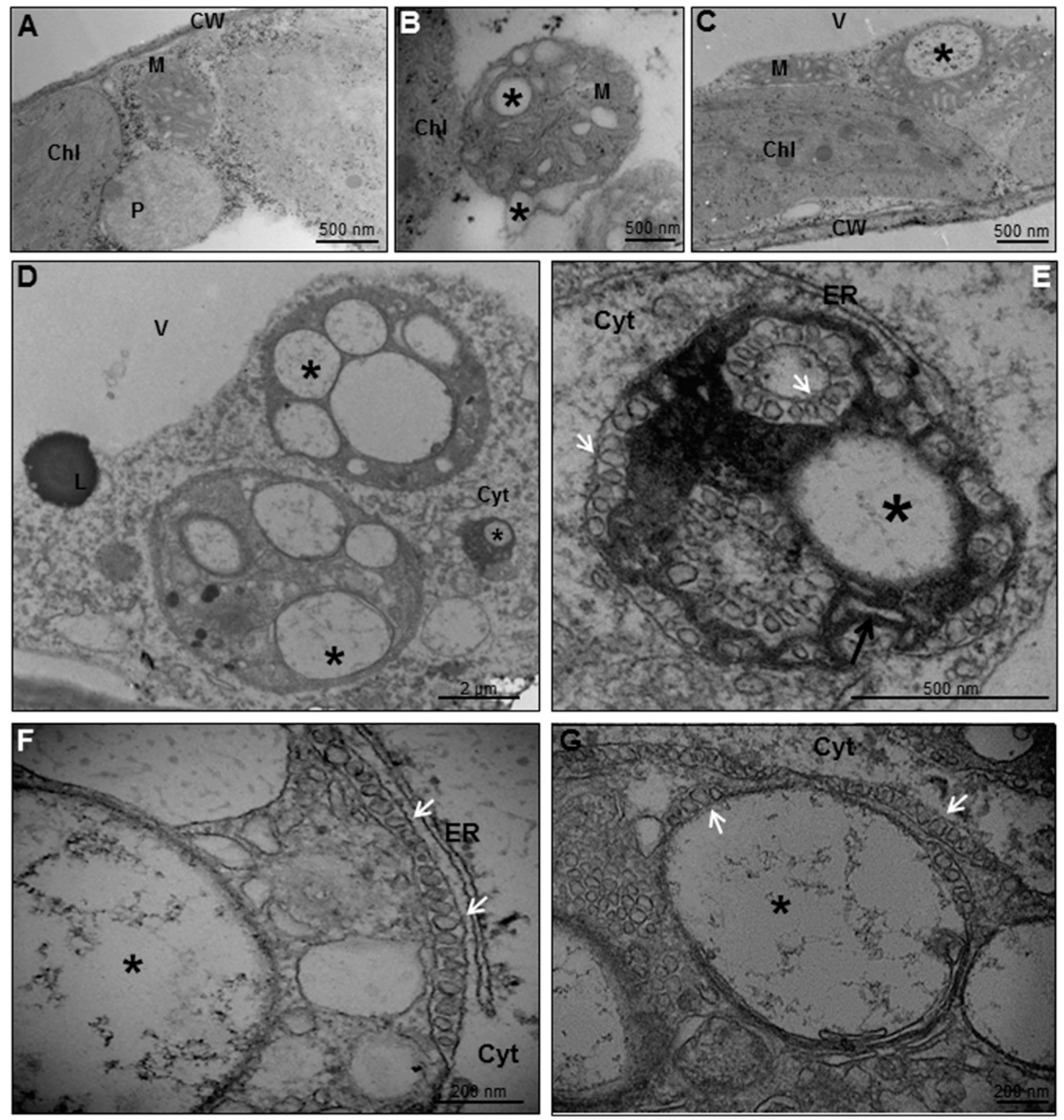

Fig. 2. Ultrastructure of Melon necrotic spot virus (MNSV)-infected cells. Samples were Spurr-embedded and studied by transmission electron microscopy. A, Healthy melon cotyledon showing normal organelle ultrastructure. B through $\mathbf{G}$, MNSV-infected melon cotyledon at 3 days postinoculation $\mathbf{B}$ and $\mathbf{C}$, Altered mitochondria $(\mathrm{M})$ with dilated cristae and separation of the mitochondrial outer membrane (star). D, The ultrastructure of various altered mitochondria present in the infected cytoplasm as well as a lipid body (L). $\mathbf{E}$ through $\mathbf{G}$, Abnormal organelles showing the presence of small vesicles inside large dilations and around the periphery of the organelle. White arrows point to bottleneck vesicles connecting either with the dilation lumen or with the cytoplasm in close association with the endoplasmic reticulum (ER) membrane. Black arrow in E points to altered cristae. Chl, chloroplast; CW, cell wall; Cyt, cytoplasm; M, mitochondria; P, peroxisome; $\mathrm{V}$, vacuole; stars point to big dilations inside altered mitochondria. 
numerous vesicles of about $50 \mathrm{~nm}$ in diameter, which might connect to an internal lumen or to the cytoplasm through a neck as shown for other viruses belonging to different families. For example, a study of the vesicles induced by Flock house virus (FHV) in mitochondria revealed the presence of the virus replication protein within similar vesicles, called there "spherules," and the connection to the outside through a channel of sufficient diameter to allow the transit of nucleotides or newly synthesized RNA or both (Kopek et al. 2007).

The small replicase protein of tombusviruses is an integral membrane protein that usually contains sequences that target to a particular cell organelle in which it associates with membranes, inducing drastic modifications in them (Martínez Turiño and Hernandez 2012; Navarro et al. 2004; Panavas et al. 2005; Rubino et al. 2000; 2001; Weber-Lotfi et al. 2002). However, the expression of this protein is normally not sufficient for the formation of specific vesicles, suggesting that other factors may be involved in the induction of these structures. For example, the cellular protein ESCRT, involved in tombusvirusinduced membrane deformations, is required for the assembly of the viral replicase (Barajas et al. 2014). The MNSV p29 has three transmembrane domains (TMD), two of them shared with p89. According to Mochizuki et al. (2009), the presence of TMD2 is crucial for its mitochondrial localization, where it may be anchored to the membrane, inducing degradation of the organelle and, hence, cell necrosis (Mochizuki et al. 2009). Our work with the ectopic expression of p29 fused to GFP has shown that this protein is targeted to mitochondria, where, unlike Carnation Italian ringspot virus-induced modifications (Rubino et al. 2000), it not only induces its disorganization but promotes the proliferation of mitochondrial membranes in a very specific manner, either by the induction of double membranes, ending in complete disruption of the organelle, or by the formation of double membranes surrounded by dilations that result in very similar structurally altered mitochondria. Since p29 and p89 share the first two TMD, it would be reasonable to propose that both are directed toward the same organelle, inducing vesicle formation with the likely presence of both viral proteins and even RNA inside.

Another differential characteristic of the MNSV replication organelle was the presence of vesicles not only in the outer membrane but also inside the organelle. The 3D reconstruction of MNSV factories showed, for first time, that the internal vesicles are generated around large dilations of real inner mitochondrial matrix. Thus, our results suggest the existence of mechanisms by which both MNSV replication proteins and newly synthesized products could be able to enter and exit this organelle and point toward the existence of microenvironments that are specifically induced by MNSV viral proteins for isolating the virus from the surrounding environment.

In view of the results described in this paper, a model of infection can be proposed for MNSV. Early translation of replication proteins would be the first event occurring after entry of the virus into the cell and desencapsidation. It has been shown that eukaryotic translation initiation factor $4 \mathrm{E}$ is required for efficient translation of MNSV RNAs (Nieto et al. 2006;
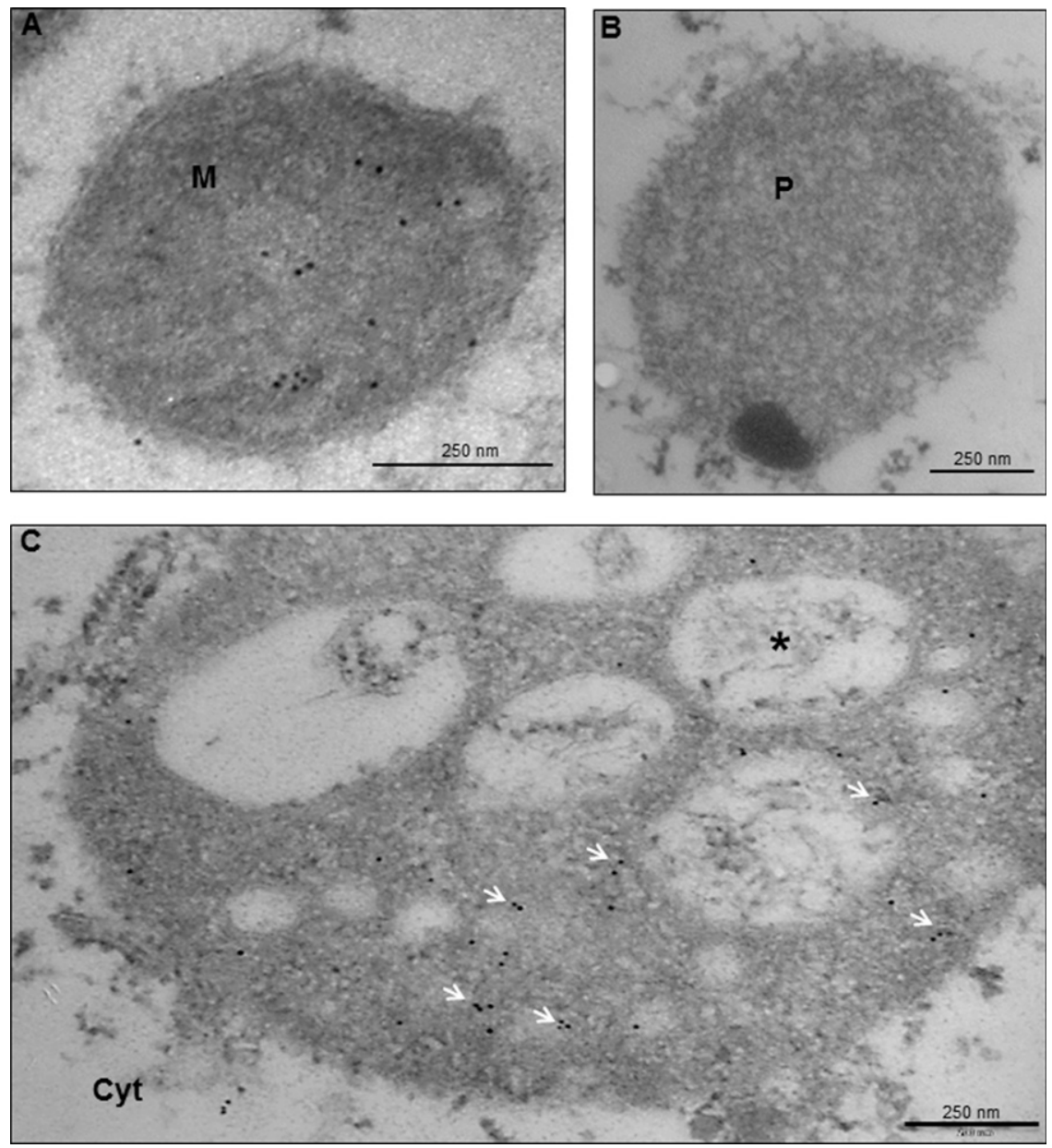

Fig. 3. Immunolocalization of the $P$ protein from the glycine decarboxylase complex in melon cotyledons embedded in LR-White. A, Mitochondria (M) from healthy tissue with specific gold labeling located in the matrix. B, Peroxisome (P) from infected tissue without labeling. C, Labeling (arrows) specifically located in the matrix of the altered mitochondria. The star points to a big dilation inside altered mitochondria. 
Truniger et al. 2008), although it is not possible to rule out its direct or indirect involvement in other processes, such as RNA transport into mitochondria ( $\mathrm{Li}$ et al. 2010), assembly of the viral replication complex (Wang et al. 2009), or subsequent translation of the newly synthetized genomic and subgenomic RNAs. Following this first event, a change of the translation into the replication function would occur, probably regulated by cis-acting elements in the RNA template and replication proteins, leading to the recruitment of viral (+) RNA to the sites of replication. In this step, it seems likely that p29 mediates the assembly and formation of MNSV replication sites. Transcription of (-) RNA would probably occur in the numerous vesicles of 50 to $70 \mathrm{~nm}$ in diameter seen in the altered mitochondria (Figs.
$2 \mathrm{E}$ through $\mathrm{G}$ and $5 \mathrm{~A}$ ). Synthesis of new genomic and subgenomic RNAs should take place here and lead to the formation of replication intermediates (dsRNA) detected in this organelle (Fig. 4G through I). Newly synthesized (+) RNA would have various fates: (i) acting as new template for replication, (ii) being encapsidated, (iii) acting as template for the translation of the structural and virus movement proteins, or (iv) moving to adjacent cells (Nagy and Pogany 2012). In fact, with the electron microscopy ISH experiments, we could localize (+) RNA, but the presence of free (-)RNA is questionable, based on recent data on tombusviruses, which showed that (-)RNA is present in a dsRNA intermediate form during the entire replication process (Kovalev et al. 2014).
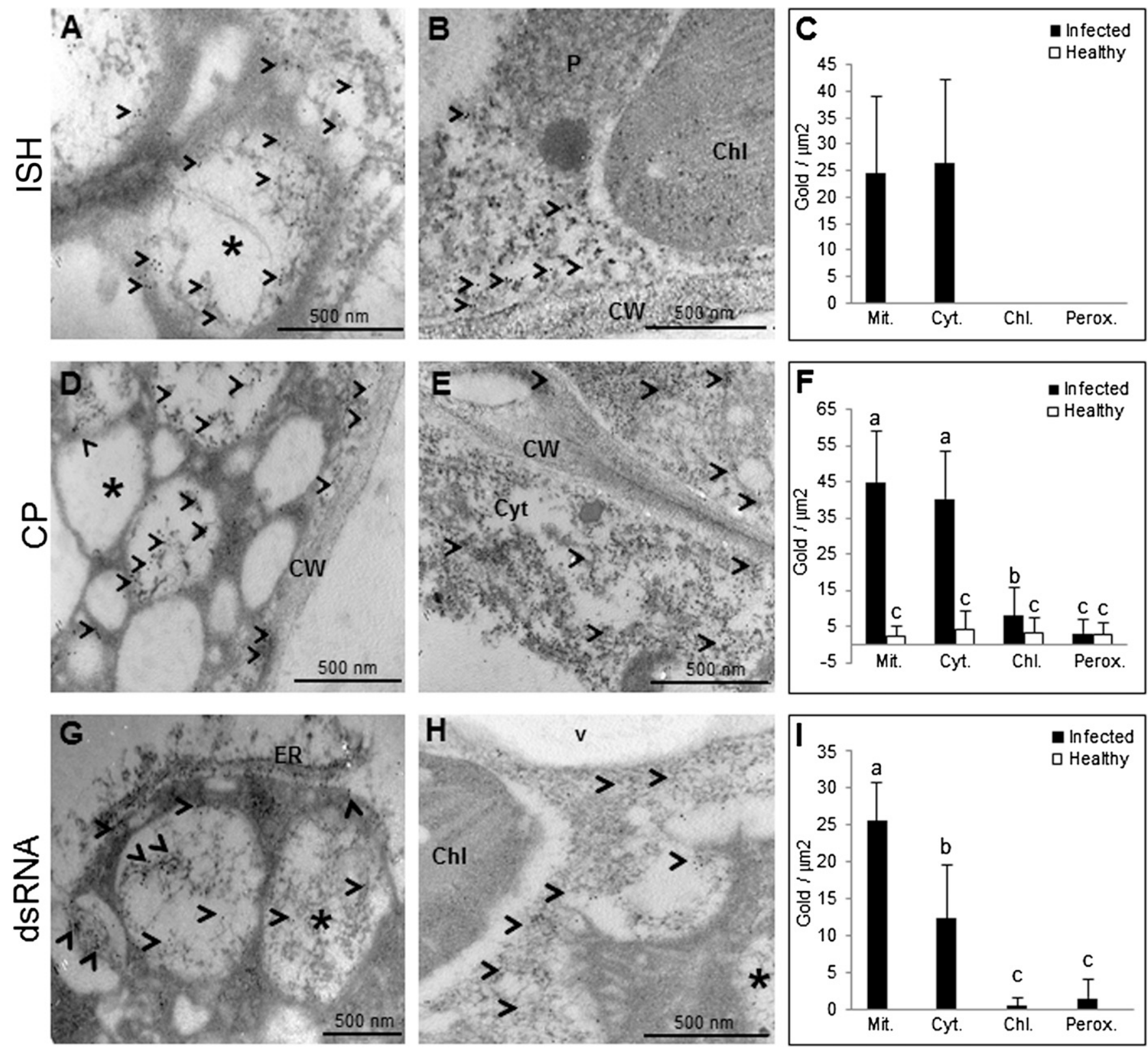

Fig. 4. Ultrastructural localization and quantification of gold labeling from A, B, and C, Melon necrotic spot virus (MNSV) RNA, D, E, and F, capsid protein (CP), and $\mathbf{G}, \mathbf{H}$, and I, double-stranded (ds)RNA in melon cotyledons embedded in LR-White. Specific localization of gold labeling in the big dilations (stars) inside altered mitochondria of infected melon cotyledon corresponding to viral RNA (A), viral CP (B), and dsRNA (C). Specific localization of gold labeling in the cytoplasm of infected cotyledons. MNSV RNA (B) and CP (E) labeling are also in the cytoplasm (Cyt), while dsRNA labeling (H) was mostly localized in the area surrounding altered mitochondria. Quantification of the subcellular distribution of gold particles per square micrometer bound to MNSV RNA (C), CP (F), or dsRNA (I). MNSV RNA labeling was very specific, with gold particles in altered mitochondria and the cytoplasm of infected cells and no background present. dsRNA was also quite specific with a very low background in infected plants and no gold particles in healthy plants. For CP antibody, the quantification was carried out in different organelles from healthy and infected tissues to determine nonspecific labeling. Different letters in the same graph correspond to significant statistical differences at $P \leq 0.05$ significance level $(t$ test; $n=25)$. Stars point to big dilations inside altered mitochondria. 
The MNSV genome encodes two small proteins (p7A and $\mathrm{p} 7 \mathrm{~B}$ ) involved in the local movement of the virus. p7A binds RNA and localizes to the cell periphery in structures that probably correspond to plasmodesmata (Genovés et al. 2009; Navarro et al. 2006), and p7B inserts into membranes of the ER in a cotranslational process (Martínez-Gil et al. 2007) and moves to Golgi and plasmodesmata, forming part of the early secretory pathway (Genovés et al. 2010, 2011; Martínez-Gil et al. 2007; Serra-Soriano et al. 2014). A striking constant during this work was the frequent association of altered mitochondria to ER and its proximity to plasmodesmata. Association of ER and altered mitochondria could respond to the need
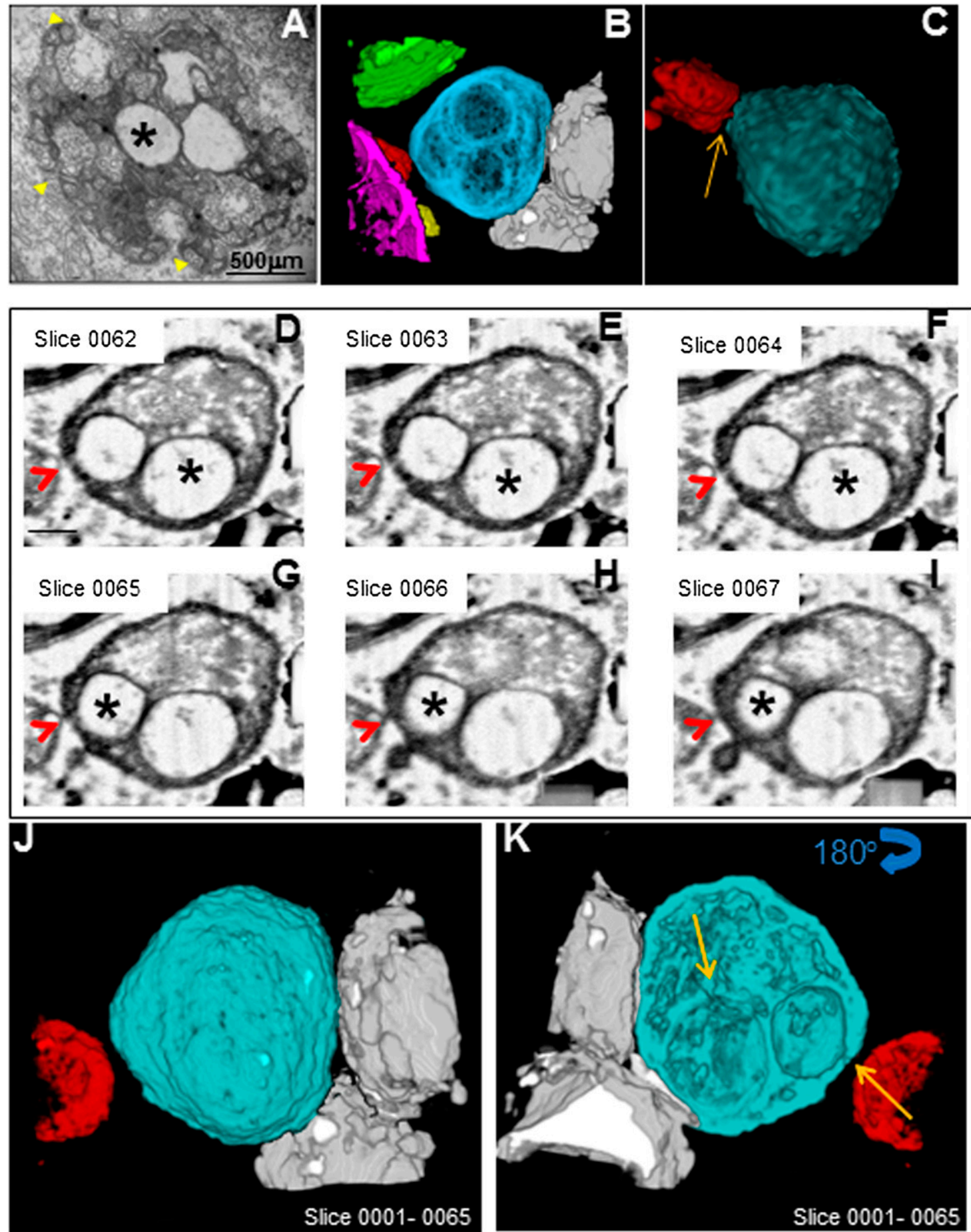

Fig. 5. Three-dimensional (3D) modeling of the Melon necrotic spot virus (MNSV) altered mitochondria by focused ion beam-field emission scanning electron microscopy (FIB/FESEM). A, Transmission electron microscopy image of the samples used for FIB/FESEM, showing altered mitochondria ultrastructure with numerous vesicles in the external membrane, as well as inside the large invaginations, the internal dilations (star), or both. B and $\mathbf{C}$, A 3D model of altered mitochondria (blue) next to a chloroplast (green) and other altered mitochondria (yellow, red, and purple), showing connections between different altered mitochondria as well as with lipid bodies (gray). D through I, Serial images used for the 3D modeling showing a pore (red arrowheads) in the external membrane connecting the lumen of the dilation (star) with the cytoplasm. J, Frontal view of the 3D representation from sections 0001 to 0065 . K, 3D modeling of the section viewed in J rotated 180 degrees. The pores between the internal dilations and with the outer membrane connecting the lumen of the dilation to the surrounding cytoplasm can be observed (yellow arrows). 
for insertion of p7B into the ER, required for MNSV cell-to-cell movement (Genovés et al. 2010, 2011). This would further facilitate their proximity to sites of p7A synthesis, which presumably would have to be translated in the vicinity of MNSV replication places to prevent nonspecific binding to nonviral RNAs (Genovés et al. 2010, 2011; Navarro et al. 2006). Alternatively, it is possible that the ER-altered mitochondria association explains the implication of this organelle in the exchange of lipids with mitochondria (Kornmann et al. 2009) and the direct relationship between lipids and viral replication described for other viruses (Sharma et al. 2010; Stapleford et al. 2009) and shown here for MNSV (Fig. 5). Intriguingly, the observed proximity of plasmodesmata to altered mitochondria might suggest the existence of mechanisms of intercellular movement acting more directly.

The limitations due to the bidimensionality of the images obtained by TEM hindered the ability to establish clear relationships between different organelles of the viral factories. However, the 3D representations of the MNSV replication organelles allowed us to show interactions between different altered mitochondria with surrounding lipid bodies (Fig. 5). The presence of lipid bodies close to or as part of viral factories has been described for numerous animal viruses (Fernández de Castro et al. 2014) like, for instance, the involvement of lipid droplets in the production of hepatitis $\mathrm{C}$ virus particles (Miyanari et al. 2007). In this work, we have described the existing connections between the MNSV replication organelles and lipid bodies, suggesting the importance of lipids for targeting viral replication complexes (Stapleford et al. 2009) or the development of replication organelles (Saito et al. 2006).

\section{MATERIALS AND METHODS}

Plants, viruses, and virus inoculation.

The melon (Cucumis melo L.) cultivar used in this study was 'Tendral' (Fitó, Barcelona, Spain). MNSV isolates MNSV264 (Díaz et al. 2002) and MNSV-M 55 (Díaz et al. 2003) were maintained and propagated in melon cotyledons or Nicotiana benthamiana leaves. Mechanical inoculation with lyophilized viral inoculum was performed as described by Díaz et al. (2003, 2004). After inoculation, plants were grown and were maintained in a greenhouse with a $16-\mathrm{h}$ photoperiod, a day and night temperature of 25 and $18^{\circ} \mathrm{C}$, respectively and day and night relative humidity of 70 and $60 \%$, respectively.

\section{TEM.}

Healthy plant areas or MNSV lesions $\left(2 \times 2 \mathrm{~mm}^{2}\right)$ both from melon and $N$. benthamiana were sampled and were fixed in a mixture of $3 \%$ paraformaldehyde and $2.5 \%$ glutaraldehyde (for Spurr embedding) or $0.5 \%$ glutaraldehyde (for LR-White embedding) in $0.1 \mathrm{M}$ (pH 7.2) sodium phosphate (NaPh.) buffer. For ultrastructural analysis, samples were postfixed in a solution of $2 \% \mathrm{OsO}_{4}$ in the same $\mathrm{NaPh}$ buffer, were dehydrated and infiltrated, and were embedded in Spurr resin at $60^{\circ} \mathrm{C}$. For immunocytochemistry, samples were not postfixed, but were dehydrated and embedded in LR-White resin at $55^{\circ} \mathrm{C}$ (FernandezGarcía et al. 2009)

For light microscopy, semithin sections were mounted on slides and toluidine blue stained. For TEM, ultrathin sections were collected on formvar-coated cooper grids and were stained with uranyl acetate and lead citrate.
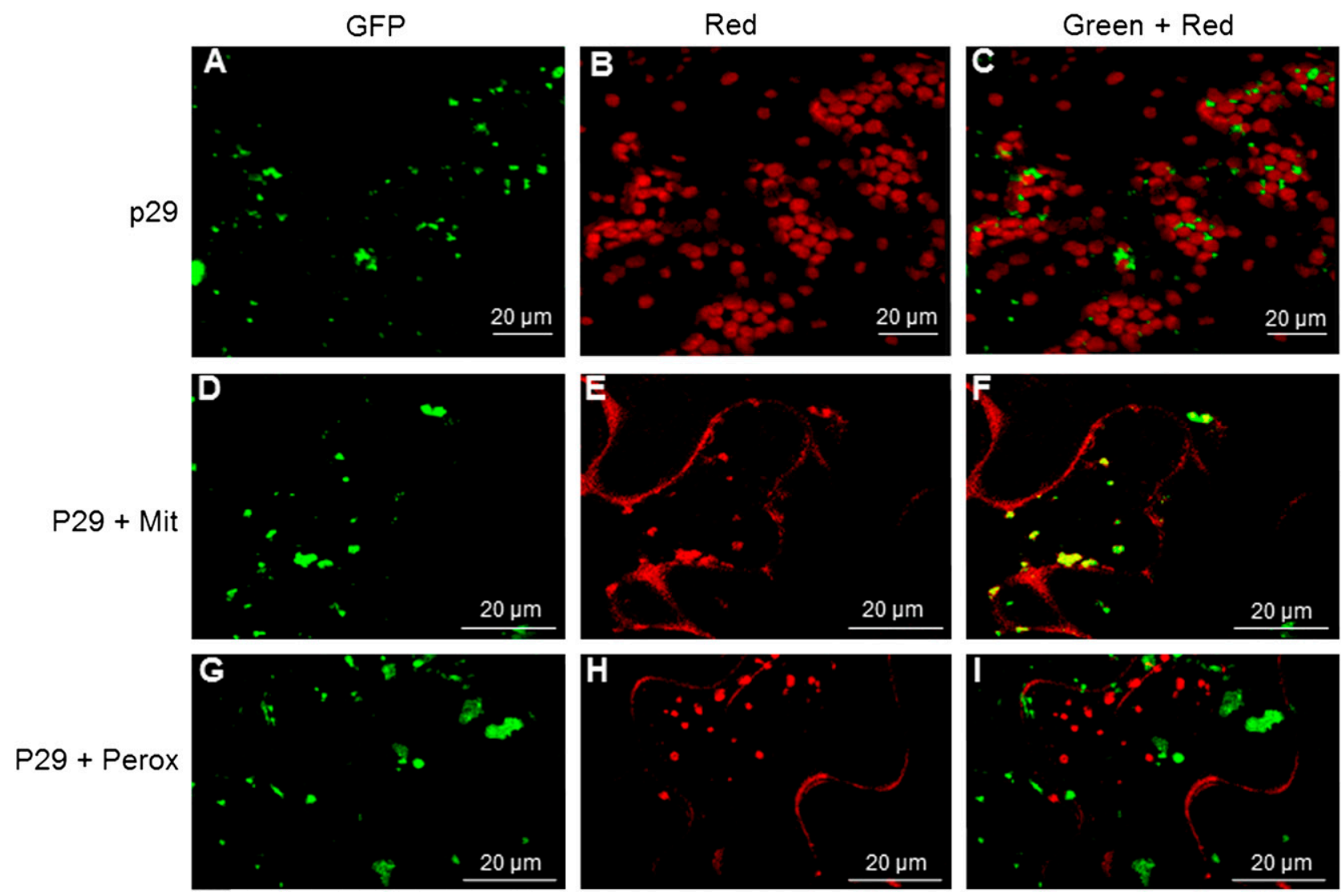

Fig. 6. Nicotiana benthamiana subcellular localization of p29-GFP protein by confocal laser scanning microscopy (CLSM). A, D, and G, Green fluorescent protein (GFP), green channel to localize Melon necrotic spot virus (MNSV) p29 replicase. B, Autofluorescence of chloroplasts is shown using the red channel $\mathbf{E}$ and $\mathbf{H}$, Expression of a mitochondrial or peroxisome marker attached to monomeric red fluorescent protein. $\mathbf{C}$ and $\mathbf{F}$, Superposition of the green and red channels showing the overlap between $\mathrm{p} 29-\mathrm{GFP}$ protein and the mitochondrial marker. 
For immunocytochemistry, ultrathin sections on formvar-coated nickel grids were employed and incubated with monoclonal antiGFP (Clontech, diluted 1:50) or polyclonals (anti-CP [Mochizuki et al. 2009] preabsorbed, diluted 1:1, and anti-Pab [Palmieri et al. 2010], diluted 1:50). Sections were then incubated with commercial secondary antibodies antimouse immunogobulin $G$ (IgG) or antirabbit IgG conjugated with 10-nm colloidal gold (1:20). Immunocytochemistry with monoclonal antibody to dsRNA (anti-dsRNA K2 mAb [Fontana et al. 2007]) was carried out as described, after treatment of the sections with proteinase $\mathrm{K}$. Controls were made on sections taken from mock-inoculated plants as well as on infected samples incubated without adding the corresponding first antibody.

For ISH experiments, grids were treated with proteinase $\mathrm{K}$ $(1 \mathrm{mg} / \mathrm{ml})$ and were hybridized for $5 \mathrm{~h}$ at $50^{\circ} \mathrm{C}$ in a hybridization solution consisting of $2 \times \mathrm{SSC}(1 \times \mathrm{SSC}$ is $0.15 \mathrm{M} \mathrm{NaCl}$ plus $0.015 \mathrm{M}$ sodium citrate), $1 \mathrm{mg} / \mathrm{ml}$ of tRNA, $10 \%$ dextran sulfate, $50 \%$ formamide and probe with a concentration of $700 \mathrm{ng} / \mathrm{ml}$. Finally, they were incubated with a commercial antidigoxigenin antibody conjugated with $10 \mathrm{~nm}$ colloidal gold (1:50). Controls were made by performing labeling on sections taken from mockinoculated plants as well as on infected samples incubated without adding the probe.

\section{Antibodies and Western blot assays.}

The antibody specificity was determined by Western blot before and after their absorption. For antibody absorption, 10 $\mathrm{mg}$ of healthy melon cotyledons were ground in liquid nitrogen, were incubated with $100 \mathrm{ml}$ of acetone, and were filtered. This process was repeated about six times until obtaining a fine and fully bleached powder that was kept in an oven at $37^{\circ} \mathrm{C}$ overnight. After complete drying, $1 \mathrm{mg}$ of the powder was incubated with $100 \mu \mathrm{l}$ of antibody diluted 1:100 (in 1× phosphate buffered saline) for $2 \mathrm{~h}$. Finally, the mixture was centrifuged and the supernatant was collected.

For the extraction of soluble and membrane-bound fraction proteins, healthy and MNSV-infected material was homogenized ( $1 \mathrm{~g}$ of material to $2 \mathrm{ml}$ of buffer) with $1 \times$ extraction buffer $(10 \%$ glycerol, $25 \mathrm{mM}$ Tris-HCL, pH 7.5, $1 \mathrm{mM}$ EDTA, $150 \mathrm{mM}$ $\mathrm{NaCl}, 10 \mathrm{mM}$ dithiothreitol, 2\% polyvinylpolypyrrolidone, proteases inhibitor (Roche) $1 \times, 0.1 \%$ Tween 20 ). The supernatant (S3) was centrifuged at $30,000 \times g$ for $20 \mathrm{~min}$ at $4^{\circ} \mathrm{C}$, obtaining the soluble protein fraction (S30) and the membrane protein fraction (p30). Both fractions were used to check for the specificity of the antibodies for MNSV proteins by separating on a $12 \%$ sodium dodecyl sulfate-polyacrylamide gel electrophoresis followed by electroblotting to a nitrocellulose membrane. Membranes were probed with polyclonal antibodies against MNSV p29, p89, and CP. Detection was done with commercial antirabbit IgG coupled to horseradish peroxidase $(1: 2,500)$ (Promega) and a chemiluminescent substrate (ECL Amersham Biosciences).

\section{Quantification and statistical analysis of gold labeling.}

Gold labeling quantitation was performed in randomly selected cells of infected tissues in which altered mitochondria were observed as well as in cells in which no altered mitochondria were present and cells from healthy plants, to
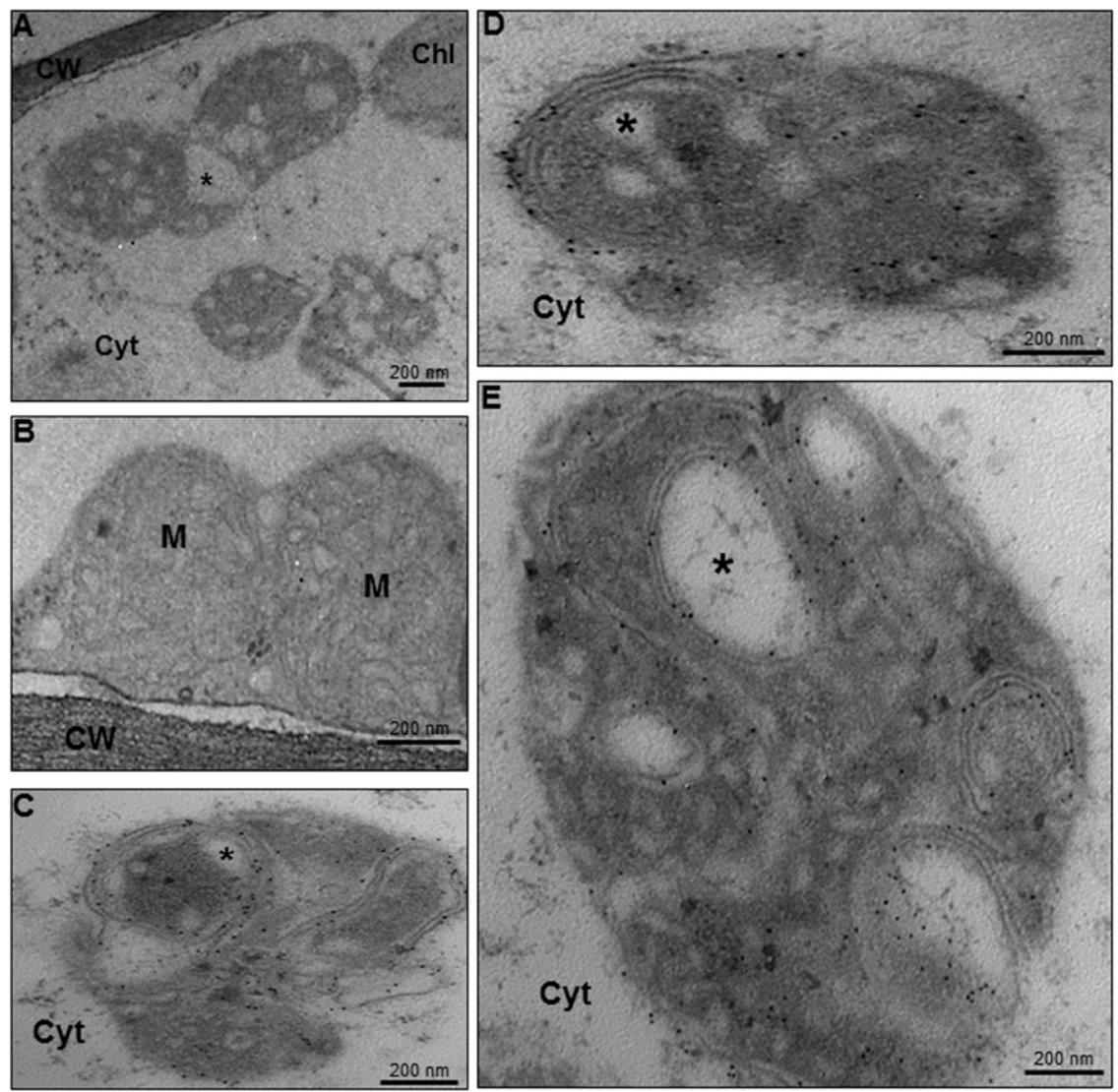

Fig. 7. Ultrastructure and immunolocalization of p29-GFP in Nicotiana benthamiana plants by immunolabeling of green fluorescent protein (GFP). A, Ultrastructure of mitochondria from $N$. benthamiana plants expressing p29-GFP showing aggregates of altered mitochondria (M) with internal dilations (stars). B, Normal mitochondria morphology in GFP-free $N$. benthamiana cells. C through E, Immunolocalization of GFP in $N$. benthamiana plants expressing p29GFP. Gold labeling is mostly located in the double membrane structures surrounding the dilations (stars) inside altered mitochondria. Chl, chloroplast; Cyt, cytoplasm; CW, cell wall. 
determine nonspecific labeling. Different cell organelles (mitochondria, chloroplasts, peroxisomes, cytoplasm, vacuoles, and cell walls) were analyzed in more than 50 different cells from three different samples. Due to the low number of gold particles found in vacuoles and cell walls, they were not taken into account for statistical analysis. Data are presented as number of gold particles per square micrometer. Gold particles in each field were counted manually. Morphometric measurements were performed with the Megaview III CCDiTEM-SIS Software Olympus coupled to Philip Tecnai 12 and the free software Image J. Finally, the data were analyzed using the $t$ test for pairwise comparisons of means $(n=25)$. Statistical differences $(P<0.05)$ were found between different treatments (infected and healthy) and between different organelles.

\section{FIB/FESEM.}

In order to enhance the signal at the low accelerating voltages used for the study, plant tissue, after fixation done as described for Spurr-embedded samples, were processed according to Deerinck et al. (2010), prolonging the postfixation with $\mathrm{OsO}_{4}$ in combination with ferrocyanide for $2 \mathrm{~h} 30 \mathrm{~min}$ and the treatment with thiocarbohidrazida for $30 \mathrm{~min}$.

Blocks were cut with a diamond knife to obtain a perfectly flat cutting surface and were studied by TEM. They were then mounted on 12.5-mm aluminum stubs and were coated with carbon (BAL-TEC SCD 005). Once in the FIB/FESEM (AURIGA Compact System, Carl Zeiss) the angle of inclination of the sample was adjusted to 54 degrees, which was later changed to 40 degrees. From the surface of the block, three different areas containing altered mitochondria were selected to be further evaluated by FIB/FESEM. Using the focused gallium ion beam, each selected area was sequentially milled across all through the selected altered mitochondria. The sliced material was removed by the gallium bean (slice thicknesses of $15 \mathrm{~nm}$ and FIB milling current of $500 \mathrm{pA})$. Most of the altered mitochondria were imaged in the middle of the body so the FIB was working until getting a complete mitochondrion.

Subsequent images were aligned, processed and 3D visualized using Fiji free software.

\section{Construction of an expression vector p29-GFP and confocal laser scanning microscopy.}

The p29 ORF from the full-length clone MNSV-M $\alpha 5$ (Díaz et al. 2003) was amplified using CE-1440 (GGGGACAAGTTT GTACAAAAAAGCAGGCTTCatggatactggattgaaag) and CE1442 (GGGGACCACTTTGTACAAGAAAGCTGGGTCgttgac caacttgaaagcc) primers, which contained the ATTR recombinant sequences. After the recombination in the pDONR201 Gateway vector by BP reaction (Invitrogen), the fragment was placed in the binary plasmid pGWB5 (Nakagawa et al. 2007) (35S promoter, C-sGFP) by LR reaction (Invitrogen) to obtain the pGWB5p29 plasmid that was transformed by electroporation into the $\mathrm{C} 58 \mathrm{C} 1 \mathrm{pCH} 32$ Agrobacterium tumefaciens strain.

Colocalization studies in $N$. benthamiana leaves were performed by infiltration with pGWB5p29 alone or in combination with mitochondrial or peroxisome markers fused to red fluorescent protein (mCherry) (Nelson et al. 2007) and the silencing suppressor p19 (Voinnet et al. 2003). Observation and imaging was performed with an inverted CLSM Leica TCS SP2 microscope (Leica Microsystems). For excitation of GFP and mCherry, 488- and 594-nm lasers were used, respectively. The emission was examined at a wavelength of 500 to 530 for GFP, 600 to 630 for the markers (mCherry), and 685 to 700 for the chlorophyll.

\section{ACKNOWLEDGMENTS}

Work was supported by grants AGL2009-07552/AGR and AGL201237390 (Ministerio de Economía y Competitividad, Spain). C. Gómez-Aix was recipient of a JAE (Consejo Superior de Investigaciones Científicas [CSIC], Spain) fellowship. For antibody donations, we thank S. Tsuda (NARO, Tsukuba, Ibaraki, Japan), C. Risco (Centro Nacional de Biotecnología-CSIC, Madrid), F. Sevilla, and D. Camejo (Centro de Edafología y Biología Aplicada de Segura [CEBAS]-CSIC). We also thank T. Nakagawa (Center for Integrated Research in Science, Shimane University, Matsue, Japan) for pGWB5 and T. Canto (Centro de Investigaciones Biológicas-CSIC, Madrid) for the cellular markers. We would also like to thank T. Castells (Servicio de Análisis de Imagen, Universidad de Murcia) M. Planes, and J. L. Moya (Servicio de Microscopia, Universidad Politécnica de Valencia) for technical 3D assistance, V. Truniger and P. Gómez for critically reading the manuscript, and M. C. Montesinos and B. Gosálvez for their excellent technical assistance (CEBAS-CSIC). M. Fon checked the English.

\section{LITERATURE CITED}

Ahlquist, P. 2006. Parallels among positive-strand RNA viruses, reversetranscribing viruses and double-stranded RNA viruses. Nat. Rev. Microbiol. 4:371-382.

Appiano, A., D’Agostino, G., Bassi, M., Barbieri, N., Viale, G., and Dell'Orto, P. 1986. Origin and function of Tomato Bushy Stunt Virusinduced inclusion bodies. J. Ultra Mol. Struct. R. 97:31-38.

Barajas, D., Martín, I. F., Pogany, J., Risco, C., and Nagy, P. D. 2014. Noncanonical role for the host Vps4 AAA+ ATPase ESCRT protein in the formation of Tomato bushy stunt virus replicase. PLoS Pathog. 10:e1004087.

Batten, J. S., Turina, M., and Scholthof, K. B. 2006. Panicovirus accumulation is governed by two membrane-associated proteins with a newly identified conserved motif that contributes to pathogenicity. Virol. J. 3:12.

Bushby, A. J., P'ng, K. M., Young, R. D., Pinali, C., Knupp, C., and Quantock, A. J. 2011. Imaging three-dimensional tissue architectures by focused ion beam scanning electron microscopy. Nat. Protoc. 6:845-858

Fernández de Castro, I., Volonté, L., and Risco, C. 2013. Virus factories: biogenesis and structural design. Cell. Microbiol. 15:24-34.

Deerinck, T. J., Bushong, E. A., Thor, A., and Ellisman, M. H.2010. NCMIR methods for 3D EM: a new protocol for preparation of biological specimens for serial block face scanning electron microscopy. National Center for Microscopy and Imaging Research, University of California, San Diego, CA, U.S.A. http://ncmir.ucsd.edu/sbfsem-protocol.pdf

Di Franco, A., and Martelli, G. P. 1984. Ultrastructure and origin of cytoplasmic multivesicular bodies induced by Carnation Italian ring spot virus. J. Gen. Virol. 65:1233-1237.

Díaz, J. A., Nieto, C., Moriones, E., and Aranda, M. A. 2002. Spanish Melon Necrotic Spot Virus isolate overcomes the resistance conferred by the recessive $n s v$ gene of melon. Plant Dis. 86:694.

Díaz, J. A., Bernal, J. J., Moriones, E., and Aranda, M. A. 2003. Nucleotide sequence and infectious transcripts from a full-length cDNA clone of the carmovirus Melon necrotic spot virus. Arch. Virol. 148:599-607.

Díaz, J. A., Nieto, C., Moriones, E., Truniger, V., and Aranda, M. A. 2004. Molecular characterization of a Melon necrotic spot virus strain that overcomes the resistance in melon and nonhost plants. Mol. Plant Microbe Interact. 17:668-675.

Fernández de Castro, I., Zamora, P. F., Ooms, L., Fernández, J. J., Lai, C. M.-H., Mainou, B. A., Dermody, T. S., and Risco, C. 2014. Reovirus forms neo-organelles for progeny particle assembly within reorganized cell membranes. MBio. 5:e00931-13.

Fernandez-García, N., Martí, M. C., Jimenez, A., Sevilla, F., and Olmos, E. 2009. Sub-cellular distribution of glutathione in an Arabidopsis mutant (vtc1) deficient in ascorbate. J. Plant Physiol. 166:2004-2012.

Fontana, J., Tzeng, W. P., Calderita, G., Fraile-Ramos, A., Frey, T. K., and Risco, C. 2007. Novel replication complex architecture in rubella replicon-transfected cells. Cell. Microbiol. 9:875-890.

Genovés, A., Navarro, J. A., and Pallás, V. 2006. Functional analysis of the five melon necrotic spot virus genome-encoded proteins. J. Gen. Virol. $87: 2371-2380$.

Genovés, A., Navarro, J. A., and Pallás, V. 2009. A self-interacting carmovirus movement protein plays a role in binding of viral RNA during the cell-to-cell movement and shows an actin cytoskeleton dependent location in cell periphery. Virology 395:133-142.

Genovés, A., Navarro, J. A., and Pallás, V. 2010. The Intra- and intercellular movement of Melon necrotic spot virus (MNSV) depends on an active secretory pathway. Mol. Plant Microbe Interact. 23:263-272.

Genovés, A., Pallás, V., and Navarro, J. A. 2011. Contribution of topology determinants of a viral movement protein to its membrane association, 
intracellular traffic, and viral cell-to-cell movement. J. Virol. 85:77977809.

Grangeon, R., Jiang, J., and Laliberté, J. F. 2012. Host endomembrane recruitment for plant RNA virus replication. Curr. Opin. Virol. 2: 683-690.

Jonczyk, M., Pathak, K. B., Sharma, M., and Nagy, P. D. 2007. Exploiting alternative subcellular location for replication: tombusvirus replication switches to the endoplasmic reticulum in the absence of peroxisomes. Virology 362:320-330.

Kopek, B. G., Perkins, G., Miller, D. J., Ellisman, M. H., and Ahlquist, P. 2007. Three-dimensional analysis of a viral RNA replication complex reveals a virus-induced mini-organelle. PLoS Biol. 5:e220.

Kornmann, B., Currie, E., Collins, S. R., Schuldiner, M., Nunnari, J., Weissman, J. S., and Walter, P. 2009. An ER-mitochondria tethering complex revealed by a synthetic biology screen. Science 325:477-481.

Kovalev, N., Pogany, J., and Nagy, P. D. 2014. Template role of doublestranded RNA in tombusvirus replication. J. Virol. 88:5638-5651.

Laliberté, J. F., and Sanfaçon, H. 2010. Cellular remodeling during plant virus infection. Annu. Rev. Phytopathol. 48:69-91.

Li, Z., Pogany, J., Tupman, S., Esposito, A. M., Kinzy, T. G., and Nagy, P. D. 2010. Translation elongation factor 1A facilitates the assembly of the tombusvirus replicase and stimulates minus-strand synthesis. PLoS Pathog. 6:e1001175.

Martelli, G. P., Di Franco, A., and Russo, M. 1984. The origin of multivesicular bodies in Tomato bushy stunt virus-infected Gomphrena globosa plants. J. Ultrastruct. Res. R. 88:275-281.

Martínez-Gil, L., Saurí, A., Vilar, M., Pallás, V., and Mingarro, I. 2007. Membrane insertion and topology of the p7B movement protein of Melon Necrotic Spot Virus (MNSV). Virology 367:348-357.

Martínez-Turiño, S., and Hernández, C. 2010. Identification and characterization of RNA-binding activity in the ORF1-encoded replicase protein of Pelargonium flower break virus. J. Gen. Virol. 91:3075-3084.

Martínez-Turiño, S., and Hernández, C. 2012. Analysis of the subcellular targeting of the smaller replicase protein of Pelargonium flower break virus. Virus Res. 163:580-591.

McCartney, A. W., Greenwood, J. S., Fabian, M. R., White, K. A., and Mullen, R. T. 2005. Localization of the tomato bushy stunt virus replication protein p33 reveals a peroxisome-to-endoplasmic reticulum sorting pathway. Plant Cell 17:3513-3531.

Mine, A., and Okuno, T. 2012. Composition of plant virus RNA replicase complexes. Curr Opin Virol 2:669-675.

Miras, M., Sempere, R. N., Kraft, J. J., Miller, W. A., Aranda, M. A., and Truniger, V. 2014. Interfamilial recombination between viruses led to acquisition of a novel translation-enhancing RNA element that allows resistance breaking. New Phytol. 202:233-246.

Miyanari, Y., Atsuzawa, K., Usuda, N., Watashi, K., Hishiki, T., Zayas, M., Bartenschlager, R., Wakita, T., Hijikata, M., and Shimotohno, K. 2007. The lipid droplet is an important organelle for hepatitis $\mathrm{C}$ virus production. Nat. Cell Biol. 9:1089-1097.

Mochizuki, T., Hirai, K., Kanda, A., Ohnishi, J., Ohki, T., and Tsuda, S. 2009. Induction of necrosis via mitochondrial targeting of Melon necrotic spot virus replication protein p29 by its second transmembrane domain. Virology 390:239-249.

Nagy, P. D., and Pogany, J. 2012. The dependence of viral RNA replication on co-opted host factors. Nat. Rev. Microbiol. 10:137-149.

Nakagawa, T., Kurose, T., Hino, T., Tanaka, K., Kawamukai, M., Niwa, Y., Toyooka, K., Matsuoka, K., Jinbo, T., and Kimura, T. 2007. Development of series of gateway binary vectors, pGWBs, for realizing efficient construction of fusion genes for plant transformation. J. Biosci. Bioeng. 104:34-41.

Navarro, B., Rubino, L., and Russo, M. 2004. Expression of the Cymbidium ringspot virus 33-kilodalton protein in Saccharomyces cerevisiae and molecular dissection of the peroxisomal targeting signal. J. Virol. 78: 4744-4752.

Navarro, J. A., Genovés, A., Climent, J., Saurí, A., Martínez-Gil, L., Mingarro, I., and Pallás, V. 2006. RNA-binding properties and membrane insertion of Melon necrotic spot virus (MNSV) double gene block movement proteins. Virology 356:57-67.

Nelson, B. K., Cai, X., and Nebenführ, A. 2007. A multicolored set of in vivo organelle markers for co-localization studies in Arabidopsis and other plants. Plant J. 51:1126-1136.

Netherton, C., Moffat, K., Brooks, E., and Wileman, T. 2007. A guide to viral inclusions, membrane rearrangements, factories, and viroplasm produced during virus replication. Adv. Virus Res. 70:101-182.

Nieto, C., Morales, M., Orjeda, G., Clepet, C., Monfort, A., Sturbois, B., Puigdomènech, P., Pitrat, M., Caboche, M., Dogimont, C., Garcia-Mas, J., Aranda, M. A., and Bendahmane, A. 2006. An eIF4E allele confers resistance to an uncapped and non-polyadenylated RNA virus in melon Plant J. 48:452-462.

Nieto, C., Rodríguez-Moreno, L., Rodríguez-Hernández, A. M., Aranda, M. A., and Truniger, V. 2011. Nicotiana benthamiana resistance to nonadapted Melon necrotic spot virus results from an incompatible interaction between virus RNA and translation initiation factor $4 \mathrm{E}$. Plant J. 66:492-501.

Ohki, T., Akita, F., Mochizuki, T., Kanda, A., Sasaya, T., and Tsuda, S. 2010. The protruding domain of the coat protein of Melon necrotic spot virus is involved in compatibility with and transmission by the fungal vector Olpidium bornovanus. Virology 402:129-134.

Palmieri, M. C., Lindermayr, C., Bauwe, H., Steinhauser, C., and Durner, J. 2010. Regulation of plant glycine decarboxylase by s-nitrosylation and glutathionylation. Plant Physiol. 152:1514-1528.

Panavas, T., Hawkins, C. M., Panaviene, Z., and Nagy, P. D. 2005. The role of the p33:p33/p92 interaction domain in RNA replication and intracellular localization of p33 and p92 proteins of Cucumber necrosis tombusvirus. Virology 338:81-95.

Riviere, C. J., and Rochon, D. M. 1990. Nucleotide sequence and genomic organization of melon necrotic spot virus. J. Gen. Virol. 71:1887-1896.

Rubino, L., Di Franco, A., and Russo, M. 2000. Expression of a plant virus non-structural protein in Saccharomyces cerevisiae causes membrane proliferation and altered mitochondrial morphology. J. Gen. Virol. 81: 279-286.

Rubino, L., Weber-Lotfi, F., Dietrich, A., Stussi-Garaud, C., and Russo, M. 2001. The open reading frame 1-encoded ('36K') protein of Carnation Italian ringspot virus localizes to mitochondria. J. Gen. Virol. 82:2934.

Russo, M., Di Franco, A., and Martelli, G. P. 1983. The fine structure of Cymbidium ringspot virus infections in host tissues. III. Role of peroxisomes in the genesis of multivesicular bodies. J. Ultrastruct. Res. 82:52-63.

Russo, M., Di Franco, A., and Martelli, G. P. 1987. Cytopathology in the identification and classification of tombusviruses. Intervirology 28: 134-143.

Saito, K., Nishijima, M., and Kuge, O. 2006. Phosphatidylserine is involved in gene expression from Sindbis virus subgenomic promoter. Biochem. Biophys. Res. Commun. 345:878-885.

Schönborn, J., Oberstrass, J., Breyel, E., Tittgen, J., Schumacher, J., and Lukacs, N. 1991. Monoclonal antibodies to double-stranded RNA as probes of RNA structure in crude nucleic acid extracts. Nucleic Acids Res. 19:2993-3000.

Serra-Soriano, M., Pallás, V., and Navarro, J. A. 2014. A model for transport of a viral membrane protein through the early secretory pathway: minimal sequence and endoplasmic reticulum lateral mobility requirements. Plant J. 77:863-879.

Sharma, M., Sasvari, Z., and Nagy, P. D. 2010. Inhibition of sterol biosynthesis reduces tombusvirus replication in yeast and plants. J. Virol. 84:2270-2281.

Stapleford, K. A., Rapaport, D., and Miller, D. J. 2009. Mitochondrionenriched anionic phospholipids facilitate flock house virus RNA polymerase membrane association. J. Virol. 83:4498-4507.

Truniger, V., Nieto, C., González-Ibeas, D., and Aranda, M. 2008. Mechanism of plant eIF4E-mediated resistance against a Carmovirus (Tombusviridae): cap-independent translation of a viral RNA controlled in cis by an (a)virulence determinant. Plant J. 56:716-727.

Turner, K. A., Sit, T. L., Callaway, A. S., Allen, N. S., and Lommel, S. A. 2004. Red clover necrotic mosaic virus replication proteins accumulate at the endoplasmic reticulum. Virology 320:276-290.

Voinnet, O., Rivas, S., Mestre, P., and Baulcombe, D. 2003. An enhanced transient expression system in plants based on suppression of gene silencing by the p19 protein of tomato bushy stunt virus. Plant J. 33: 949-956.

Wang, R. Y., Stork, J., Pogany, J., and Nagy, P. D. 2009. A temperature sensitive mutant of heat shock protein 70 reveals an essential role during the early steps of tombusvirus replication. Virology 394:28-38.

Weber-Lotfi, F., Dietrich, A., Russo, M., and Rubino, L. 2002. Mitochondrial targeting and membrane anchoring of a viral replicase in plant and yeast cells. J. Virol. 76:10485-10496.

Westaway, E. G., Khromykh, A. A., and Mackenzie, J. M. 1999. Nascent flavivirus RNA colocalized in situ with double-stranded RNA in stable replication complexes. Virology 258:108-117.

\section{AUTHOR-RECOMMENDED INTERNET RESOURCE}

Fiji software: fiji.sc/Fiji 